\title{
Mestrado Profissional em Ensino na Saúde no Brasil: avanços e desafios a partir de políticas indutoras
}

\section{Professional Master's Programs in Health Teaching in Brazil: advances and challenges with respect to incentives policies}

\section{Maestría Profesional en Enseñanza en la Salud en Brasil: avances y retos a partir de políticas inductoras}

Rosana Quintella Brandão Vilela, doutora em Medicina (Hematologia) pela Universidade Federal de São Paulo (Unifesp), professora Associada IV e vice-coordenadora do Programa de Pós-Graduação em Ensino na Saúde, modalidade Mestrado Profissional, da Universidade Federal de Alagoas (Ufal), Maceió, AL, Brasil. E-mail: zanavilela@gmail.com.

Nildo Alves Batista, livre-docente em Educação Médica pela Universidade Federal de São Paulo (Unifesp), professor titular do Departamento de Saúde, Educação e Sociedade e vice-coordenador do Programa de Pós-Graduação Ensino em Ciências da Saúde, modalidade Mestrado Profissional, da Unifesp, Santos, SP, Brasil. E-mail: nbatista@unifesp.br.

\section{Resumo}

Este estudo objetivou conhecer as repercussões da indução dos mestrados profissionais em Ensino na Saúde, procurando subsídios para o aprimoramento e a sustentabilidade dos programas. 0 trabalho teve caráter qualitativo exploratório, reunindo análise documental e realização de entrevistas semiestruturadas com coordenadores dos programas, predominando a análise temática dos dados coletados. Evidenciaram-se duas categorias: "Avanços dos programas em Ensino na Saúde na modalidade profissional" e "Desafios na implementação da política indutora”. Os avanços foram identificados pelo crescimento do 
número de programas, distribuição regional e agregação dos programas na área de Ensino da Capes. Os desafios remetem para a ausência de financiamento, pouca valorização do mestrado profissional e pouca clareza dos critérios de avaliação dos programas.

Palavras-chave: Mestrado Profissional. Políticas Públicas. Sustentabilidade.

\section{Abstract}

The aim of this study was to identify the repercussions from the incentive for Professional Master's Programs in Education in Health, seeking subsidies for the improvement and sustainability of the programs. The study was exploratory and qualitative, gathering documental analysis and semi-structured interviews with coordinators of the programs, emphasizing a thematic analysis of the collected data. Two categories were observed: Advances in the health education programs of professional mode and Challenges in implementing the induction policy. The advance was identified by the growing number of programs; regional distribution and aggregation of programs in the Teaching Area, as defined by Capes. The challenges refer to: lack of financing, poor appreciation of the professional master and lack of clarity of the criteria for evaluating the programs.

Keywords: Professional Masters. Public Policies. Sustainability.

\section{Resumen}

Este estudio tuvo como objetivo conocer las repercusiones de la inducción de la maestría profesional en enseñanza en salud, buscando subvenciones para la mejora y sostenibilidad de los programas. El trabajo tuvo un carácter investigador cualitativo, recopilando análisis documental y llevando a cabo entrevistas semiestructuradas a coordinadores de los programas, predominando el análisis temático de los datos recogidos. Se pusieron de manifiesto dos categorías: “Avances 
de los programas en enseñanza de la salud en modalidad profesional" y "Retos en la implementación de la política inductora". Los avances fueran identificados por el crecimiento del número de programas; la distribución regional y la incorporación de los programas en el área de enseñanza de la Capes. Los retos se remiten a ausencia de financiación, poca valorización de la maestría profesional y poca claridad de los criterios de evaluación de los programas.

Palabras clave: Maestría Profesional. Políticas Públicas. Sostenibilidad.

\section{Introdução}

A formação de profissionais para a integralidade do cuidado em saúde representa uma estratégia do Sistema Único de Saúde (SUS) para enfrentar o grande desafio de otimizar seus recursos numa proposta inovadora e corajosa de um sistema universal e equânime. Esses processos formativos devem considerar o acelerado ritmo de evolução do conhecimento, as mudanças do método de trabalho em saúde, as transformações decorrentes de aspectos demográficos e epidemiológicos, com vistas ao equilíbrio entre a excelência técnica e a relevância social. Espera-se formar cidadãos-profissionais críticos e reflexivos, com conhecimentos, habilidades e atitudes que os tornem aptos a atuar em um sistema de saúde qualificado e integrado.

Em ação conjunta desde 2002, os Ministérios da Saúde (MS) e da Educação (MEC) fomentam políticas objetivando a implantação das Diretrizes Curriculares Nacionais (DCN) e uma maior aproximação da formação em saúde com a concepção da integralidade do cuidado humano. Para tanto, os diagnósticos (BATISTA, 1998; FEUERWERKER, 2002; BATISTA, 2005) apontam a qualificação para a docência dos profissionais que atuam junto à graduação e à residência na área da saúde, bem como a produção do conhecimento e as inovações tecnológicas, como estratégias fundamentais para atendimento a esses princípios filosóficos, organizacionais e operativos preconizados pelo SUS. 
Na busca para atender a alta demanda pela qualificação, em 2008, surge o sistema Universidade Aberta do SUS (UNA-SUS) com o objetivo de promover o treinamento em serviço de profissionais atuando em programas de saúde da família e atenção primária à saúde (CAMPOS et al., 2010).

Dessa maneira, a educação a distância foi compreendida como mais uma forma de atender a essa necessidade de criação de pósgraduações, inclusive de mestrado profissional, desafiando o aparelho formador a buscar o equilíbrio entre o "fazer-e-o-saber" e o "saberpara-fazer".

O MP emerge como um tipo de formação que, além de qualificar tecnicamente os profissionais para utilizarem-se de ferramentas científicas no exercício de suas funções, compromete-se com a formação de um profissional mais eficaz e mais eficiente (SANTOS et al., 2012).

A partir desses pressupostos sobre os MPs, em 2010 foi lançada a política do Pró-Ensino na Saúde, que teve como um dos eixos a indução de mestrados profissionais em Ensino na Saúde (MPES), acreditando-se na possibilidade de esta modalidade de pós-graduação responder, de maneira mais rápida e eficiente, à implementação das políticas públicas para a formação na área (QUELHAS et al., 2005).

Essas políticas indutoras dos MPES tiveram como marco um seminário nacional que finalizou com a apresentação do documento Recomendações para Elaboração de Projetos de Mestrados Profissionais em Ensino na Saúde(BRASIL, 2010). O objetivo deste documento foi o de estabelecer, com base nos consensos alcançados durante o seminário, orientações para a elaboração de projetos referentes a novos programas de mestrado profissional na área de Ensino na Saúde, atendendo ao Edital 005/CAPES/DAV - Chamada de Novas Propostas de Cursos de Mestrado Profissional.

Esse documento (BRASIL, 2010) trouxe como principais características dos programas de mestrado profissional em Ensino na Saúde: 
1. Compromisso com a formação de recursos humanos em senso estrito para o avanço do ensino na saúde com vistas ao fortalecimento do SUS;

2. Formação de futuros mestres que atuem no ensino na saúde, preferencialmente, no cotidiano dos serviços de saúde;

3. Caráter multidisciplinar da proposta, envolvendo diferentes áreas, culturas e práticas do conhecimento;

4. Produção de conhecimento com base na investigação de situações relacionadas à prática do ensino na saúde na sua interface com as evidências científicas da área e dos serviços de saúde;

5. Desenvolvimento de intervenções a partir de pesquisas realizadas nos serviços de saúde que produzam impacto no SUS;

6. Programa com ênfase na transformação das práticas profissionais;

7. Possibilidade de criação de núcleo disseminadores e incentivadores regionais, com desenvolvimento de propostas interinstitucionais;

8. Definição de políticas e estratégias para a divulgação dos resultados das pesquisas, com destaque para publicações em periódicos qualificados da área;

9. Definição de políticas e estratégias para a divulgação dos resultados das pesquisas e desenvolvimento de produtos de intervenção para a transformação das práticas, inclusive junto aos gestores acadêmicos, dos serviços de saúde, dos profissionais dos serviços de saúde e para o controle social;

10. Equipes proponentes preferencialmente interdisciplinares e multiprofissionais, envolvendo cursos da área da saúde, com as necessárias interfaces com as áreas de ciências humanas, quando couber. Como consta na portaria normativa sobre MP, quando couber, a equipe poderá contar com profissionais não portadores do título de doutor que participarão como colaboradores do programa na condição de co-orientadores e participantes de disciplinas; 
11. Possibilidade de intercâmbio interinstitucional ser considerado como um mecanismo de aprimoramento da equipe;

12. Participação da instituição proponente e dos docentes envolvidos em programas de incentivo à melhoria da graduação em saúde desenvolvidos pelo MS e pelo MEC, tais como o Pró-Saúde, PET-Saúde, UNA-SUS, Telessaúde e FAIMER Brasil, e as relacionadas à educação técnica profissional, entre outros.

Neste estudo buscou-se conhecer as repercussões da indução dos MPES, procurando subsídios para o aprimoramento e para a sustentabilidade dos programas. Entendemos que a relevância do estudo se deve não apenas à necessidade de se avançar nesse sentido, mostrando a importância de se realizar uma reflexão teórica acerca da indução e da sustentabilidade das propostas ligadas às políticas públicas, mas também ao reconhecimento da complexidade que envolve a identidade do MP, como ainda um campo repleto de interrogações.

\section{Percurso metodológico}

A pesquisa realizada foi de caráter exploratório, com metodologia qualitativa que, de acordo com Triviños (1987, p. 109), "permite ao investigador aumentar sua experiência em torno de determinado problema”.

A amostra teve âmbito nacional, visando corresponder ao que determinam os objetivos da pesquisa. Teve, como limite, estudar os programas em Ensino na Saúde existentes e reconhecidos pela Capes até o ano de 2013. Esse recorte possibilitou a identificação de 13 programas de MPES existentes no país (Quadro 1). 
Quadro 1. Relação dos programas de MPES identificados na pesquisa

\begin{tabular}{|l|l|}
\hline \multicolumn{1}{|c|}{ NOME Do PROGRAMA } & \multicolumn{1}{|c|}{ INSTITUIÇÃo } \\
\hline Mestrado Profissional em Ensino em Ciências da Saúde & Unifesp \\
\hline Mestrado Profissional em Ensino na Saúde & Ufal \\
\hline Mestrado Profissional em Ensino em Ciências da Saúde & UNIR (Rondônia) \\
\hline Mestrado Profissional em Ensino na Saúde & UFG \\
\hline Mestrado Profissional Ensino em Saúde & Famema-SP \\
\hline Mestrado Profissional em Educação nas Profissões da Saúde & PUC-SP (Sorocaba) \\
\hline Educação para o Ensino na Área de Saúde & FPS PE \\
\hline Mestrado Profissional em Ensino na Saúde & UFRGS \\
\hline Mestrado Profissional em Ensino na Saúde & UFVJM (MG) \\
\hline Ensino na Saúde: Formação docente interdisciplinar para o SUS & UFF \\
\hline Mestrado Profissional Ensino e Saúde na Amazônia & Uepa \\
\hline Mestrado Profissional em Ensino na Saúde & Uece \\
\hline Mestrado Profissional em Ensino na Saúde & UFRN \\
\hline
\end{tabular}

Fonte: elaboração dos autores

Neste estudo, entende-se como essência de um MPES o programa que tem como objetivo tomar a prática docente do mestrando como ponto de partida para empreender mudanças no cotidiano do ensinar e aprender no âmbito dos serviços de saúde e das IES, em um movimento de ação-reflexão-ação.

Para a coleta de dados, optou-se por dois instrumentos: análise documental e realização de entrevistas semiestruturadas com os coordenadores dos programas que estavam em funcionamento há pelo menos um ano, para aprofundar o conhecimento sobre as experiências desafiadoras dessa modalidade de pós-graduação.

Como primeiro momento, foi realizado o estudo documental dos dados dos programas na página da Capes e identificados os cursos de pós-graduação voltados para o Ensino na Saúde, na modalidade MP, reconhecidos e recomendados por essa coordenação, ou seja, aqueles que obtiveram nota igual ou superior a 3 na última avaliação e que, portanto, atendiam aos requisitos básicos de qualidade e, consequentemente, tinham permissão para a emissão de diplomas 
de mestrado com validade nacional. Em seguida, foi realizado um estudo exploratório e investigativo da realidade, visando a uma "maior familiaridade com o problema, com vistas a torná-lo mais explícito ou a construir hipóteses" (GIL, 2002, p. 41). Dessa forma, a pesquisa de campo pôde contribuir para a concretização dos objetivos propostos.

O roteiro de entrevista semiestruturada foi elaborado a partir dos seguintes núcleos direcionadores: desafios, nós críticos e mecanismos de sustentabilidade dos programas. Uma carta-convite, contendo informações, esclarecimentos, relevância e objetivos do estudo, foi enviada por meio dos endereços eletrônicos aos sujeitos da pesquisa, juntamente com o link de acesso ao Termo de Consentimento Livre e Esclarecido (TCLE).

Foram contatados 11 coordenadores dos 13 programas de MP em funcionamento. Destes, nove aceitaram participar, respondendo ao roteiro de entrevista, que foi encaminhado para armazenamento dos dados no GoogleDocs. Esse número não implicou limitações aos objetivos propostos na pesquisa.

Como procedimentos de análise de dados, foi realizada análise temática, uma das técnicas de análise de conteúdo. Inicialmente, trabalhou-se na organização dos documentos selecionados e na transcrição das entrevistas. Em seguida, foi realizada a leitura flutuante e a identificação do material de análise, constituindo assim o corpus da pesquisa. Por fim, foram identificadas as unidades de registro e de contexto para a formulação das categorias de análise e a interpretação dos núcleos de significação encontrados (MINAYO, 2006).

O estudo foi submetido ao Comitê de Ética em Pesquisa da Universidade Federal de São Paulo (Unifesp) - Plataforma Brasil e aprovado com o Parecer $n^{\circ}$ 428.955. Todos os participantes assinaram o Termo de Consentimento Livre e Esclarecido. E, para preservar o sigilo dos entrevistados, eles foram nomeados por ordem sequencial de E1 a E9. 


\section{Resultados e discussão}

Os procedimentos de organização dos documentos e das entrevistas com o objetivo de conhecer as repercussões da indução dos MPs em Ensino na Saúde e procurar subsídios para o aprimoramento e a sustentabilidade dos programas possibilitaram a identificação de duas categorias temáticas e suas relações. A primeira revelou os "Avanços dos programas em Ensino na Saúde na modalidade profissional", e a segunda mostrou os "Desafios na implementação da política indutora".

Os "Avanços dos programas em Ensino na Saúde na modalidade profissional" foram agrupados em três dimensões: (a) crescimento do número de programas; (b) distribuição regional dos programas; (c) agregação na Área de Ensino da Capes.

Os documentos analisados indicam uma forte evolução (12 novos cursos) dos MPs na área de Ensino na Saúde, durante o período de 2010 a 2013 (Gráfico 1).

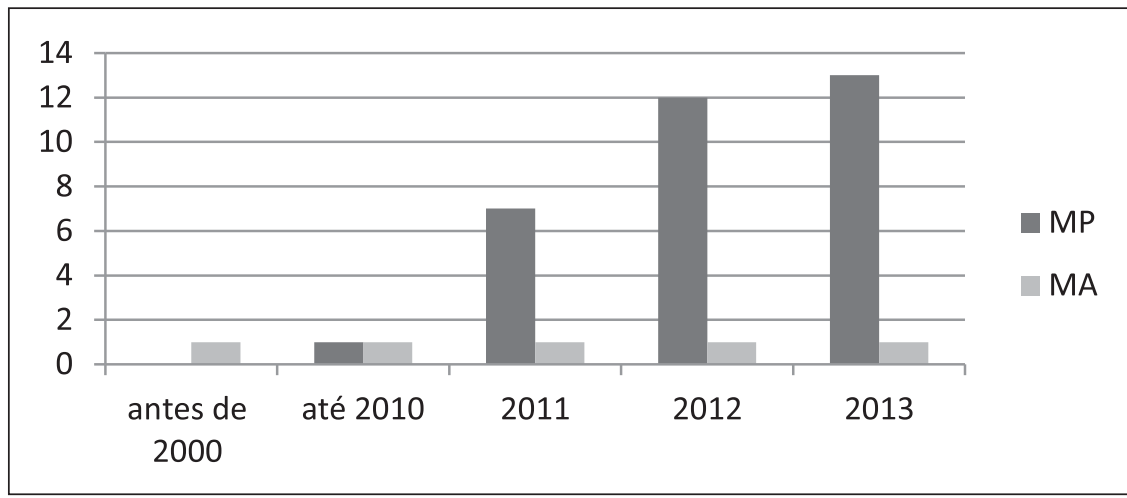

Fonte: http://www.capes.gov.br/

$\mathrm{MP}=$ mestrado profissional

MA= mestrado acadêmico

\section{Gráfico 1. Número de novos cursos de MPES no período de 2010 -2013}

Observa-se um crescimento expressivo após a implantação da política indutora (Pró-Ensino na Saúde), visto que, antes do seminário, havia apenas um MPES, o Mestrado Profissional em Ensino em Ciências da Saúde - Unifesp, e um outro na modalidade acadêmico, vinculado à UFRJ. 
As falas dos coordenadores reforçam a necessidade de crescimento, ao mesmo tempo em que permitiram a identificação da alta demanda dos profissionais por esta modalidade de pós-graduação (PG), que cursam em média com turmas de 20 alunos:

"Como exemplo, no atual processo seletivo [...], tivemos 202 inscrições revelando a alta procura e a necessidade de se criar estratégias de aproveitamento deste contingente de profissionais que desejam e necessitam a qualificação profissional” (E6).

Quelhas et al. (2005, p. 104), em estudo realizado sobre objetivos e o posicionamento estratégico do MP no ambiente da pós-graduação brasileira, assinalam “'[...] que o mestrado profissional, em função de seus pressupostos, pode dar respostas mais ágeis para a implementação das políticas públicas no País”.

Pesquisas realizadas com egressos de MP (RUAS, 2003; ARAÚJO; AMARAL, 2006) destacam como principais contribuições do curso: maior confiança e segurança para atuar em ambientes complexos e interdisciplinares, como ensino; formação da rede de relacionamento, principalmente por se tratar de profissionais com carreiras mais estabelecidas, o que permitiu a construção de diferentes visões de mundo, mais heterogêneas e, consequentemente, complexas; maior capacidade de analisar mais profundamente os cenários e as situações do mundo real, e postura crítica e reflexiva em relação à atuação docente e à possibilidade de atuação em pesquisas, o que poderia contribuir para a atuação na docência e na resolução de problemas.

Entende-se que a adesão das instituições de ensino superior e dos profissionais a essa modalidade de PG é proporcional à crença no seu potencial estratégico na formação de profissionais que se utilizam de ferramentas científicas para identificar e analisar problemas vivenciados na prática do Ensino na Saúde, além de propor inovações no setor. Associa-se também essa adesão ao momento atual de expansão do ensino superior público e privado na área da saúde, visto que esta condição demanda profissionais qualificados para atuarem como docentes formais ou preceptores do serviço. 
A partir dos dados é também possível inferir que, apesar do grande crescimento da oferta de cursos de MPES, o número ainda é insuficiente para atender à demanda dos profissionais que buscam qualificação na área.

Em relação à distribuição regional dos programas, observa-se que todas as regiões do país estão contempladas com alguns dos 13 programas pesquisados, sendo sua quase totalidade (11) ofertada por instituições públicas.

Nos documentos analisados verifica-se que, do total de 13 programas, cinco encontram-se na região Sudeste, quatro na região Nordeste, dois na região Norte e um nas regiões Centro-Oeste e Sul. Observa-se que a preocupação com a distribuição geográfica regional da pós-graduação no Brasil tem sido tema constante de debate, uma vez que se torna essencial para analisar a realidade dos MPES no país.

Santos e colaboradores (2012, p. 50) comentam sobre a expansão de MPs no país, destacando que, sendo essa
[...] uma perspectiva válida e o mestrado profissional puder efetivamente ser tomado como estratégia para implementar políticas públicas de formação em saúde, um ponto crucial seria planejar intersetorialmente sua regulação e ordenação, já que a expansão desta modalidade na área precisará guardar coerência e favorecer a consecução de princípios estruturantes do sistema único de saúde brasileiro, como a universalidade e a equidade.

Nesse sentido, a análise da distribuição regional e espacial dos MPES pelo Brasil apresenta indícios de potencialidade para a qualificação das práticas profissionais nesse nivel, em uma área estratégica para o desenvolvimento do país.

Outro ponto de destaque é a maior oferta dessa modalidade de PG em Ensino na Saúde pelas instituições públicas. Esse resultado vai ao encontro do padrão observado da oferta nas demais áreas das ciências da saúde (SANTOS et al., 2012), e retratam o papel que o Estado brasileiro tem assumido na expansão dos MPs, tanto no campo do Ensino como no conjunto das ciências da saúde. 
A agregação na área de Ensino da Capes, a terceira subcategoria, representa os avanços da indução dos MPES quanto à agregação destes programas na nova área de Ensino, criada em 2011 pelo Conselho Superior da Capes. Esta área foi proposta como ampliação do escopo da área de Ensino de Ciências e Matemática e teve como objetivo avaliar novas propostas de cursos de mestrados acadêmicos, doutorados e MPs que trabalhassem com pesquisa e formação de recursos humanos no ensino de qualquer conteúdo, e não apenas em Ciências e Matemática (ARAÚJO-JORGE et al., 2013).

Os documentos pesquisados mostram que existe uma tendência (em seis dos 13) de os MPES se agregarem na nova área de Ensino. Essa agregação é vista como avanço, com a possibilidade de maiores ganhos na luta pela sustentabilidade dos MPs, bem como o aperfeiçoamento dos indicadores e dos processos de avaliação da área.

Em relação aos desafios na implementação da política indutora, foi possivel observar que os MPES possuem especificidades gerenciais cujo enfrentamento envolve o universo do ensino e da saúde, impondo desafios na estrutura operacional dos programas. Nessa dimensão, emergem três subcategorias importantes: ausência de financiamento, pouca valorização do MP e carência de critérios de avaliação dos programas.

A ausência de financiamento é um importante desafio de caráter operacional, citado de alguma maneira por todos os entrevistados. Em alguns momentos, a legislação afirma que a Capes dará apoio ao MP tal qual ao mestrado acadêmico (MA), mas, em outros, é omissa ou insuficiente. As Portarias de 1995 (BRASIL, 1995) e 1998 (BRASIL, 1998) declaram que o MP tem vocação para o autofinanciamento.

Segundo Santos e Hortale (2014), os parâmetros para avaliação de 1999 explicitam que "a Capes, em princípio não financia cursos de MP. Mediante ação indutora poderá vir a apoiar iniciativas voltadas para o desempenho de funções básicas do Estado" (p. 2.148). Ainda no mesmo artigo, referem que o texto do documento de 2002 omite qualquer participação da Capes nesse sentido, apontando que "a instituição 
promotora deve formalizar o compromisso com o oferecimento, manutenção e conclusão do curso" (p. 2.148).

As Portarias de número 7 e 17, ambas de 2009 (BRASIL, 2009a, 2009b), declaram em seu art. 11 que, "Salvo em áreas excepcionalmente priorizadas, o mestrado profissional não pressupõe, a qualquer título, a concessão de bolsas de estudos pela Capes". É com base neste artigo que surge, em 2011, a portaria normativa que concede bolsas de formação para professores da rede pública, matriculados em cursos de MP oferecidos por meio do Sistema Universidade Aberta do Brasil (BRASIL, 2011).

O MP em análise nesta pesquisa trata de uma estratégia no contexto do processo de reorientação da formação profissional em saúde visando à integralidade do cuidado, induzida por agências governamentais, cuja parceria esperada seria do Estado, por meio dos Ministérios (Saúde, Educação e C\&T) ou das IES.

A ausência do apoio financeiro é destacada na fala de quase todos os coordenadores, tanto de instituições públicas como privadas:

"(é um desafio) a valorização desse tipo de formação com o incentivo de bolsas de estudo ou ajuda de custos para deslocamentos e diárias aos mestrandos" (E3).

"(É um nó crítico não ter) verba para financiamento dos projetos de pesquisa" (E4).

Menandro (2010, p. 371), refletindo sobre o tema na área de Administração, assinala que:

[...] as características atuais dos Mestrados Profissionais poderiam revelar que a exigência de financiamento independente das fontes governamentais de recursos pode representar um filtro pelo qual só passem profissionais já absorvidos por empresas ou por instituições públicas (ou porque essas empresas ou instituições estão financiando o projeto, ou porque têm renda que permite assumir essa despesa, muitas vezes alta, com a formação complementar). Interessados que não estejam em uma dessas condições terão dificuldade de se engajar em Mestrados Profissionais. 
Ao mesmo tempo em que houve homogeneidade na fala sobre a falta de apoio financeiro, identificada até mesmo na exclusão dos MPs dos editais da Capes, os gestores apontam também para mecanismos de sustentabilidade como:

"(Utilizamos) verba da universidade de chamadas internas; recursos das inscrições dos processos seletivos [...]” (E4).

"[...] algumas parcerias foram realizadas com secretaria estadual e municipal da saúde" (E7).

“[...] a Pró-Reitoria de Pós-Graduação tem adotado um valor anual para depósito nos cursos de pós-graduação por aluno da universidade. Por enquanto, não temos tido dificuldades" (E8).

Mesmo nos programas buscando sustentabilidade, as dificuldades em realizar ou manter essa parceria, principalmente quando se trata de instituição pública, foram identificadas nas falas dos coordenadores:

"Por ocasião da aprovação pela Capes, foram alocados recursos pela SGTES/MS na Secretaria de Estado da Saúde [...]. Mas não conseguimos utilizar estes recursos na primeira turma. O governo da época se recusou a repassar os recursos para a universidade federal tocar o curso" (E5).

"Embora seja preconizada a autossustentação dos mestrados profissionais, a própria legislação que rege as instituições públicas acaba dificultando a captação de recursos por meio de parcerias junto aos setores privados" (E6).

A reflexão de Teixeira (2006) sobre o MP em Saúde Coletiva demonstra o potencial estratégico dessa modalidade de PG na "integração ensino-serviço”. Apoiar os MPs na área é visto como possibilidade de conjugar a produção do conhecimento ao desafio cotidiano de encontrar solução para os problemas, desde formular políticas até desenvolver estratégias que incidam efetivamente sobre estruturas e práticas insuficientes para o enfrentamento e resolução dos problemas existentes.

O exposto direciona a um questionamento feito por Fischer (2010) sobre a razão pela qual os MPs não poderiam ser oferecidos pelas 
universidades públicas, de forma gratuita, com financiamento similar ao acadêmico. Também explicita a necessidade de implantação de programa de apoio aos cursos de MP, que não possuem subsídio externo, dentro das IES, para que se desenvolvam adequadamente.

Ainda em relação aos desafios foi citada, como segunda subcategoria, a "pouca valorização institucional do MP", tema que tem sido discutido por alguns autores. Paixão (2013), em seu artigo de revisão sobre os MPs, discorre sobre o quanto um novo formato educacional, como é o caso, traz discussões sobre o novo e o estabelecido.

O MP foi idealizado no documento que criou a pós-graduação brasileira, o Parecer n 977/1965 (BRASIL, 1965), no qual a pósgraduação era pensada como um sistema com dois eixos de formação (acadêmico e profissional), mas, apenas o eixo acadêmico foi exercitado integralmente por três décadas, respondendo sozinho pelo primeiro degrau para a formação acadêmica científica, necessária à carreira universitária (LOPES NETO et al., 2005; FISCHER; WAIANDT, 2012).

Os primeiros cursos de MP datam da década de 1990, envolvendo, segundo Fischer (2003, 2010), a sedução de novos modelos curriculares com quadro docente permeado de profissionais e professores doutores, com articulações claras e significativas entre teoria e prática e a conciliação dos estudos com o trabalho. O risco da proposta se expressa em conciliar os contrários, os eixos acadêmico e profissional.

A criação de MP requer que a instituição valorize a iniciativa, a prática como um elemento formativo. Esse sentimento não foi percebido pelos coordenadores, que assim se expressam:

“(Há) pouco conhecimento institucional (sobre o MP)” (E2).

"A maior interação poderia agregar mudanças e melhorias, reconhecendo-o como o mestrado acadêmico" (E3).

Na visão de Piquet, Leal e Terra (2005), parte da comunidade acadêmica rejeitou (e ainda rejeita) os MPs, considerando-os cursos de "segunda linha", mesmo pouco conhecendo as suas especificidades. Para Fischer (2005), a inércia estrutural do sistema de pós-graduação 
brasileiro, a hipervalorização dos mestrados acadêmicos e o esforço das áreas para serem conhecidas como produtoras de conhecimento científico criaram uma rejeição ao formato diferenciado proposto nos MPs.

Virmond (2002) alega que há nas instituições uma falsa percepção de que o MP pode desaboná-las e que apenas os programas acadêmicos dão prestígio e promovem a qualificação da universidade, o que se revela um equívoco. Fischer (2005) assegura que os MPs são cursos acadêmicos, uma vez que a grande maioria existe no ambiente da academia. Paixão e Bruni (2013) apresentam toda uma contribuição para um melhor entendimento da proposta de um MP e seus valores.

Diante da fala dos coordenadores, corroborada com a reflexão dos autores disponíveis na literatura, emerge a inevitável indagação: as instituições de ensino superior estão considerando a potencialidade do MP na sua missão com a sociedade? O MP, ao formar indivíduos capazes de transformar suas práticas, também realiza transformações na academia? Surge aqui um campo para futuras pesquisas.

A "carência de critérios de avaliação dos programas de MP" surge como a terceira e última subcategoria. Esta avaliação, como foi estabelecida em 1998, é orientada pela Diretoria de Avaliação/Capes e realizada com a participação da comunidade acadêmico-científica por meio de consultores ad hoc. A avaliação é atividade essencial para assegurar e manter a qualidade dos cursos de mestrado e doutorado no país.

Os documentos de área são referências para a avaliação, agora quadrienal, dos cursos em funcionamento. Neles estão descritos o estado atual, as características e as perspectivas, assim como os quesitos considerados prioritários na avaliação dos programas de pósgraduação pertencentes a cada uma das 48 áreas de avaliação. A partir de 2009, os critérios do sistema de avaliação para o MP tornaram-se distintos dos do MA.

O desafio da avaliação é concreto para os programas e aparece na fala dos coordenadores: 
"(Para aprimoramento dos programas, a Capes poderia) considerar substancialmente a avaliação de produções técnicas na área, como parte dos critérios para estabelecimento de conceito" (E7).

Independentemente de ser modalidade profissional ou acadêmica, a avaliação dos programas ainda é muito contaminada pela lógica da PG acadêmica, em que a publicação em periódicos continua sendo o principal produto nas avaliações. Essa é uma questão também levantada por um dos coordenadores:

\footnotetext{
"Percebe-se que há um esforço da Capes para mudar este perfil, mas ainda prevalece e passa a ser a maior dificuldade dos programas de MP que têm mais dificuldades para publicar" (E9).
}

Giacomazzo e Leite (2014), analisando dados da Capes de 2011, mostraram que a maioria dos cursos de MP do país está classificada com o conceito 3. Pelas exigências naturais do próprio contexto histórico dos MPs e impulsionadas pelas análises que emergiram das avaliações anteriores, a Capes organizou nova ficha de avaliação. Nesta ficha, ainda é evidente a maior ênfase no Quesito IV - Produção intelectual e profissional e seus respectivos critérios, que incluem diferentes formas de produção. No entanto, outros aspectos que compõem a identidade e a natureza dos MPs são relevantes.

Fischer (2010) afirma que o sistema de avaliação vigente estimula a qualidade e reprime a criatividade e a inovação, atributos fundamentais de processos artesanais, dos quais o MP é um exemplo pleno de significado. Menandro (2010) argumentou que é possivel ter impacto positivo sobre a criatividade e a inovação, desde que haja uma avaliação menos preocupada em estabelecer hierarquias rígidas e conformadas a determinados tipos de distribuição. Na visão desse autor, os MPs exigem relativização do princípio de comparabilidade, base da avaliação dos programas acadêmicos. É justamente esse um dos pontos discutidos, pois os MPs não precisam seguir a mesma base fundamentada para os demais cursos.

Paixão et al. (2014), utilizando a técnica Delphi para analisar possiveis indicadores de impacto de cursos de MP, apontam: produção 
técnica; acompanhamento profissional do egresso; aplicabilidade dos projetos de pesquisa; execução técnica; publicação em periódicos de cunho técnico; intercâmbios, parcerias, colaborações com outras instituições de ensino e pesquisa; parcerias com empresas e organizações profissionais, entre outros. A eficácia foi a principal dimensão entre os indicadores apontados.

A reflexão continuada sobre as particularidades do MP e de cada uma das áreas de avaliação da Capes vem gerando o desenvolvimento de indicadores específicos. É imprescindivel o estímulo à participação dos docentes e coordenadores dos cursos no processo de construção dessas propostas.

Os desafios para a sustentabilidade dos MPES indicados nesta pesquisa coincidem com o documento elaborado pelo Fórum Nacional dos Mestrados Profissionais (Foprof), em Florianópolis. O documento aprovado na Assembleia Ordinária do Fórum finaliza com o seguinte texto:

[...] As IES e os centros de pesquisa aceitaram o desafio e promoveram os MP. A Portaria Normativa n 17, de 28 de dezembro de 2009, ratifica que os MP são uma política pública de Educação Superior.

No entanto, os grandes desafios continuam:

- A falta de adesão do mundo do trabalho aos Mestrados Profissionais;

- A elaboração de um modelo de financiamento dos Mestrados

Profissionais nas IES públicas;

- Fomento aos Mestrados Profissionais através da articulação dos governos federais, estaduais e municipais em algumas áreas estratégicas; - Aperfeiçoamento da Avaliação da CAPES dos Mestrados Profissionais; - Avaliação ser realizada pelos pares com experiência em Mestrados Profissionais.

Que as demandas de desenvolvimento e sustentabilidade do Brasil da próxima década sejam fonte de inspiração para transformar nossos anseios em realidade (FOPROF, 2011 p. 10). 


\section{Considerações finais}

A fim de tecer as considerações finais deste estudo, torna-se necessário retomar algumas inquietações que suscitaram a investigação sobre os avanços e as experiências desafiadoras da indução dos MPES.

Deve-se destacar a difícil tarefa de reunir todos os dados deste trabalho, garantindo um distanciamento entre sujeito e objeto. Foi necessário, em muitos relatos, ler e reler com muito cuidado para não valorizar apenas os aspectos positivos da pesquisa, influenciada pelas convicções profissionais dos pesquisadores e seus trabalhos como protagonistas na construção de MPES, considerando-os importantes espaços de formação.

Nesse sentido, foi realizada a análise e interpretação dos dados, buscando elementos dos documentos do portal Capes e das entrevistas com coordenadores, bem como dados da literatura que levantassem diferentes tensionamentos sobre o MP.

Cabe ressaltar a disponibilidade dos coordenadores para as entrevistas: poder estar em muitos lugares diferentes, com falas e realidades distintas consistiu um ponto forte deste estudo.

Com este trabalho foi possível constatar o papel que o Estado brasileiro tem assumido na expansão da oferta dos mestrados profissionais no campo do Ensino na Saúde, com presença desses programas em todas as regiões do país, quase sempre capitaneados por instituições públicas. E, além disso, foi possivel perceber que sua expansão está vinculada às perspectivas de qualificação das práticas profissionais para o ensino no contexto do SUS.

O crescimento da oferta de cursos corrobora a necessidade de profissionais mais bem qualificados atuando na formação em saúde. Porém, é necessário analisar com cautela as consequências diretas disso, equalizando o justificado entusiasmo com uma avaliação cuidadosa dos riscos a serem evitados para que o aumento do número de cursos tenha os ganhos qualitativos esperados. É importante cuidar dos rumos 
da expansão dessa modalidade e caracterizá-la melhor para que possa assumir seu lugar no contexto da PG brasileira.

Os sinais de aumento da demanda pelos MPES apontam para a necessidade de se buscarem formas de articulação entre diferentes modalidades de educação permanente e a pós-graduação, profissional e/ou acadêmica, para que seja possível atendê-la. Responder a essa demanda certamente vai requerer maior flexibilidade e criatividade na formatação dos programas que, agregados em uma única área de avaliação da Capes, encontrarão maiores facilidades para esse enfrentamento.

Além de constatar a presença do Estado induzindo a criação dos MPES, foi possivel identificar situações operacionais desafiadoras que põem em risco a sustentabilidade desses programas. Entre o grupo de coordenadores entrevistados, houve uma homogeneidade de opiniões sobre a necessidade de apoio institucional e governamental para os programas. Os MPES foram pós-graduações induzidas por políticas públicas, cujo financiamento merece ser revisto pela Capes, bem como pelas instituições de ensino superior, para que eles se desenvolvam adequadamente.

Constata-se que, embora os MPES sejam ofertados pelas IES, estas não necessariamente os tratam da mesma maneira com que trata os mestrados acadêmicos. Ou seja, parece ainda frágil a percepção das IES sobre a potencialidade dos MPs na sua missão com a sociedade. Daí a pouca valorização dessa modalidade de PG. Vislumbra-se aqui um campo de futuras pesquisas.

Foi possível perceber, ainda, que a avaliação dos programas surge como mais um desafio a ser enfrentado pelos MPs. Identificou-se a preocupação com a produção intelectual, principalmente com a científica, quando a discussão atual se faz também focada no impacto do produto final (produção técnica ou educacional) e na avaliação do egresso.

Tais resultados, apontando para uma visão de PG ainda predominantemente acadêmica sobre a avaliação, demonstram a 
necessidade de se estimular a participação dos docentes e coordenadores dos cursos no processo de construção das propostas de avaliação das áreas da Capes, ao mesmo tempo em que suscitam pesquisas futuras sobre o tema.

Por fim, este trabalho não responde a todas as inquietações sobre os avanços e os desafios da indução dos MPs em Ensino na Saúde, mas, com certeza, traz elementos que podem contribuir para a reflexão e para a construção da sustentabilidade dos MPES, algo importante para toda a sociedade.

Recebido em 28/08/2015 Aprovado em 24/11/2015

\section{Referências}

ARAÚJO-JORGE, T. C.; MESQUITA, D.; RÔÇAS, G. Entrevista - Em 2013 o maior desafio foi consolidar a nova Área e realizar sua avaliação trienal, recuperando o sentimento de pertencimento e de confiança na Área de Ensino. Polyphonia, v. 24, n. 2, p. 353-362, 2013.

ARAÚJO, M. S. T.; AMARAL, L. H. Impactos do mestrado profissional em ensino de ciências e matemática da Unicsul sobre a atividade docente de seus estudantes: do processo de reflexão às transformações na prática pedagógica. RBPG, Brasília, v. 3, n. 5, p. 150-166, 2006.

BATISTA, N. A.; SILVA, S. H. S. 0 professor de medicina - conhecimento, experiência e formação. São Paulo: Loyola, 1998.

BATISTA, N. et al. O enfoque problematizador na formação de profissionais da saúde. Rev. Saúde Pública, v. 39, n. 2, p. 231-237, 2005.

BRASIL. Ministério da Educação e Cultura. Parecer n 977/65. Definição dos Cursos de Pós-Graduação. Documenta, n 44. Brasília, DF, 1965.

Ministério da Educação. Portaria Normativa nº 47, de 17 de outubro de 1995. Dispõe sobre o documento "Programa de Flexibilização 
do Modelo de Pós-Graduação Senso Lato em Nivel de Mestrado" no âmbito da Fundação Coordenação de Aperfeiçoamento de Pessoal de Nivel Superior CAPES. Brasília, DF, 1995. Disponível em: <http://www. foprof.org.br/documentos/portaria-no-47-17-outubro-1995.pdf>. Acesso em: 1 ago. 2015.

Ministério da Educação. Portaria Normativa $\mathbf{n}^{\circ} \mathbf{8 0}$, de 16 de dezembro de 1998. Dispõe sobre o reconhecimento dos mestrados profissionais e dá outras providências. Disponivel em: <http://www. foprof.org.br/documentos/portaria-no-80-16-dezembro-1998.pdf>. Acesso em: 1 ago. 2015.

Ministério da Educação. Portaria Normativa n 7, de 22 de junho de 2009a. Dispõe sobre o mestrado profissional no âmbito da Fundação Coordenação de Aperfeiçoamento de Pessoa de Nível Superior - CAPES. Disponível em: <http://www.foprof.org.br/documentos/portarianormativa-mec-n07-22-06-2009.pdf>. Acesso em: 1 ago. 2015.

Ministério da Educação. Portaria Normativa n 17, de 28 de dezembro de 2009b. Dispõe sobre o mestrado profissional no âmbito da Fundação Coordenação de Aperfeiçoamento de Pessoa de Nivel Superior - CAPES. Disponível em: <http://www.foprof.org.br/documentos/ portaria-normativa-mec-n17-28-12-2009.pdf>. Acesso em: 1 ago. 2015.

Ministério da Educação. Portaria $\mathbf{n}^{\circ}$ 289, de 21 de março de 2011. Dispõe sobre a concessão de bolsas de formação para professores da rede pública matriculados em cursos de mestrado profissional. Disponível em: <http://www.foprof.org.br/documentos/portarianormativa-mec-n289-21-03-2011.pdf>. Acesso em: 1 ago. 2015.

CAMPOS, F. E. et al. O desafio dos processos e do mercado de trabalho na APS - o desafio da formação e qualificação. In: BRASIL. Ministério da Saúde. Secretaria de Atenção à Saúde. Departamento de Atenção Básica. Memórias da Saúde da Família no Brasil. Brasília: Ministério da Saúde, 2010. p. 124-132. (Série I. História da Saúde no Brasil). Disponível em: <http://bvsms.saude.gov.br/bvs/publicacoes/memorias_saude_ familia_brasil.pdf>. Acesso em: 23 nov. 2015. 
FEUERWERKER, L. C. M. Além do discurso de mudança na educação médica: processos e resultados. São Paulo: Hucitec; Londrina: Rede Unida; Rio de Janeiro: Associação Brasileira de Educação Médica, 2002.

FISCHER, T. Seduções e riscos: a experiência do mestrado profissional. RAE - Revista de Administração de Empresas, São Paulo, v. 43, n. 2, p. 119-123, 2003.

- Mestrado profissional como prática acadêmica. RBPG, Brasília, v. 2, n. 4, p. 24-29, 2005.

Sobre a maestria, profissionalização e artesanato intelectual. Revista de Administração Contemporânea, v. 14, n. 2, p. 353-359, 2010.

FISCHER, T.; WAIANDT C. A educação profissional e os desafios do desenvolvimento brasileiro: uma proposta integradora entre a pósgraduação, a educação básica e os mundos do trabalho. RBPG, Brasília, v. 9, n. 16, p. 87 - 110, 2012.

FOPROF - Fórum Nacional dos Mestrados Profissionais. Mestrado Profissional: reflexões e proposições para sua avaliação e sustentabilidade. Florianópolis-SC, 2011. Disponível em: <http://www.foprof.org.br/ download/reflexoes-proposicoes.pdf>. Acesso em: 1 ago. 2015.

GIACOMAZZO, G.; LEITE, D. O Mestrado Profissional no Âmbito das Políticas Públicas na Educação: reflexões sobre a produção do conhecimento científico. ETD - Educação Temática Digital, v. 16 n. 3 p. 475-493 set./dez. 2014. Disponível em: <https://www.fe.unicamp.br/ revistas/ged/etd/article/download/6888/pdf_119>. Acesso em: 30 jul. 2015.

GIL, A. C. Como elaborar projetos de pesquisa. 4. ed. São Paulo: Atlas S/A, 2002.

MENANDRO, P. R. M. Réplica 2 - Mestrado Profissional, você sabe com quem está falando? Rev. adm. contemp. [on-line], v. 14, n. 2, p. 367-371, abr. 2010. Disponivel em: <http://www.scielo.br/scielo.php?script=sci_ 
arttext\&pid=S1415-65552010000200012\&lng=en\&nrm=iso>. Acesso em: 27 jul. 2015.

MINAYO,M.C.S.Odesafiodoconhecimento-pesquisaqualitativaem Saúde. 9. ed. São Paulo: Hucitec, 2006

MINISTÉRIO DA EDUCAÇÃO. Capes - Coordenação de Aperfeiçoamento de Pessoal de Nivel Superior. Recomendações para projetos de mestrados profissionais em ensinos na saúde. 2010. Disponível em: <http:// www.capes.gov.br/servicos/sala-de-imprensa/36-noticias/3682recomendacoes-para-projetos-de-mestrados-profissionais-emensinos-na-saude>. Acesso em: 30 jul. 2013.

NEGRET, F. A identidade e a importância dos mestrados profissionais no Brasil e algumas considerações para sua avaliação. RBPG, Brasília, v. 5, n. 10, p. 217-225, dez. 2008.

PAIXÃO, R. B.; BRUNI, A. L. Mestrados profissionais: características, especificidades, diferenças e relatos de sucesso. Administração: Ensino e Pesquisa (RAEP), Rio de Janeiro, v. 14, n. 2, p. 279-309, 2013.

PAIXÃO, R. B. et al. Avaliação de Mestrados Profissionais: Construção e Análise de Indicadores à Luz da Multidimensionalidade. Ensaio: aval. pol. públ. educ., Rio de Janeiro, v. 22, n. 83, p. 505-532, abr./jun. 2014.

PIQUET, R.; LEAL, J. A. A.; TERRA, D. C. T. Mestrado profissional: proposta polêmica no Sistema Brasileiro de Pós-Graduação - o caso do planejamento regional e urbano. RBPG, Brasília, v. 2, n. 4, p. 30-37, 2005.

QUELHAS, O. L. G.; FARIA FILHO, J. R.; FRANÇA, S. L. B. O mestrado profissional no contexto do sistema de pós-graduação brasileiro. RBPG, Brasília, v. 2, n. 4, p. 97-104, jul. 2005.

RIBEIRO, R. J. O mestrado profissional na política atual da Capes. RBPG, Brasília, v. 2, n. 4, p. 8-15, jul. 2005.

RUAS, R. Mestrado modalidade profissional: em busca da identidade. RAE - Revista de Administração de Empresas, São Paulo, v. 43, n. 2, p. 55-63, 2003. 
SANTOS, G. B.; HORTALE, V. A.; AROUCA, R. Mestrado Profissional em Saúde Pública: caminhos e identidade. Rio de Janeiro: Ed. Fiocruz, 2012.

SANTOS, G. B.; HORTALE, V. A. Mestrado Profissional em Saúde Pública: do marco legal à experiência em uma instituição de pesquisa e ensino. Ciência \& Saúde Coletiva, Rio de Janeiro, v. 19, n. 7, p. 2.143-2.155, 2014. Disponivel em <http://www.scielo.br/scielo.php?script=sci_ arttext\&pid=S1413-81232014000702143\&lng=en\&nrm=iso $>$. Acesso em: 1 Ago. 2015.

TEIXEIRA, C. Significado estratégico do mestrado profissionalizante na consolidação do campo da Saúde Coletiva. In: LEAL, M. do C.; FREITAS, C. M. (Orgs.). Cenários possiveis: experiências e desafios do mestrado profissional na saúde coletiva. Rio de Janeiro: Editora Fiocruz, 2006.

TRIVIÑOS, A. N. S. Introdução à pesquisa em ciências sociais: a pesquisa qualitativa em educação. São Paulo: Atlas, 1987.

VIRMOND, M. Mestrado profissional - uma síntese. Salusvita, v. 21, n. 2, p. 117-130, 2002. 